\title{
Espécies de Gorybia Pascoe (Coleoptera, Cerambycidae, Piezocerini) ocorrentes na Bolívia
}

\author{
Maria Helena M. Galileo ${ }^{1,3}$ \& Ubirajara R. Martins 2,3 $^{2,3}$
}

\begin{abstract}
${ }^{1}$ Museu de Ciências Naturais, Fundação Zoobotânica do Rio Grande do Sul, Caixa postal 1188, 90001-970 Porto Alegre-RS, Brasil. galileo@fzb.rs.gov.br ${ }^{2}$ Museu de Zoologia, Universidade de São Paulo. Caixa Postal 42494, 04218-970 São Paulo-SP, Brasil. urmsouza@usp.br ${ }^{3}$ Pesquisador do CNPq.
\end{abstract}

\begin{abstract}
Species of Gorybia Pascoe (Coleoptera, Cerambycidae, Piezocerini) occurring in Bolivia. The genus Gorybia (Cerambycinae, Piezocerini) consists of 45 described species with seven species recorded from Bolivia. Nine new species are described herein from Bolivia: G. abnormalis sp. nov.; G. alveolata sp. nov.; G. asyka sp. nov.; G. florida sp. nov.; G. inarmata sp. nov.; G. longithorax sp. nov.; G. guenda sp. nov.; G. tuberosa sp. nov. and G. wappesi sp. nov. A key to the species now known to occur in Bolivia is included.
\end{abstract}

KEYWORDS. Insecta; key to species; Neotropical; new species; new records; taxonomy.

O gênero Gorybia foi estabelecido por Pascoe (1866) para uma espécie do Brasil, G. martes. Bates (1870) acrescentou ao gênero G. pusilla e G. simplicior e Gounelle (1909) adicionou G. ruficauda e G. castanea. Martins (1976) descreveu 34 espécies e Martins (2003) publicou a revisão do gênero. Com acréscimos de Martins \& Galileo (2007, 2010), Galileo \& Martins (2008, 2010) e Martins et al. (2009), o gênero passou a encerrar 45 espécies. Dessas, uma ocorre da Nicarágua ao Panamá, sendo as demais sul-americanas, com ocorrência da Colômbia à Argentina.

Duas espécies foram erroneamente registradas para a Bolívia por Wappes et al. (2006): G. adiaphora Martins, 1976 e G. tibialis Martins, 1976 e devem ser excluídas da fauna desse país. Wappes et al. (2011) acrescentaram G. semiopaca Martins, 1976 na lista das espécies bolivianas.

Nesta contribuição, descrevemos mais nove espécies da Bolívia o que eleva para 54 o número de espécies do gênero Gorybia e 16 ocorrentes na Bolívia

As siglas usadas ao longo do texto correspondem a ACMS, American Coleoptera Museum, San Antonio; AMNH, American Museum of Natural History, New York; MCNZ, Museu de Ciências Naturais, Fundação Zoobotânica do Rio Grande do Sul, Porto Alegre; MNKM, Museu Noel Kempff Mercado, Santa Cruz de la Sierra; MZSP, Museu de Zoologia, Universidade de São Paulo, São Paulo; USNM, The National Museum of Natural History, Washington.

\section{Chave para as espécies de Gorybia ocorrentes na Bolívia}

1. Superfície elitral microesculturada totalmente ou com microescultura na metade anterior (aparência opaca nas áreas microesculturadas)

1'. Élitros sem microescultura (aparência brilhante) ........ 3

2(1). Élitros inteiramente e densamente microesculturados; (pronoto fortemente microesculturado, sem alvéolos na re- gião central; metasterno microesculturado lateralmente e esparsamente pubescentes).. G. veneficella Martins, 1976

2'. Élitros com a metade anterior microesculturada e a metade posterior lisa G. semiopaca Martins, 1976

3(1). Élitros com duas colorações (pode ser metade apical, sutura, faixas ou manchas de outra cor) ........................ 4

3' Élitros unicolores ....................................................... 7

4(3). Élitros com pouco menos da metade anterior preta e o restante da superfície avermelhada; pronoto brilhante; lado ventral do corpo brilhante, sem pubescência e sem pontuação G. instita Martins, 1976

4' Élitros com manchas ou faixas de outra cor ................. 5

5(4). Élitros amarelo-acastanhados com faixa ou mancha, irregular, acastanhada; base dos élitros, às vezes, também acastanhada ........................ G. picturata Martins, 1976

5'. Élitros castanho-avermelhados com faixa longitudinal junto à sutura mais avermelhada ou preta ..................... 6

6(5). Pronoto sem sulco centro-longitudinal ou com sulco centro-basal diminuto; élitros com faixa longitudinal junto à sutura, da base até o quarto apical, preta

G. suturella Martins, 1976

6'. Pronoto com sulco do adelgaçamento basal até o terço apical; élitros com faixa longitudinal junto à sutura avermelhada. (Figs. 3, 4) G. asyka sp. nov.

7(3). Ápices elitrais obliquamente truncados e desarmados (constrição basal do protórax marcada, bem mais estreita do que a contrição anterior que é muito discreta). (Figs. 7, 8)

7'. Ápices elitrais com outro padrão G. inarmata sp. nov.

8(7). Ápices elitrais emarginados com espinho curto no ângulo marginal e projeção larga, arredondada, no ângulo

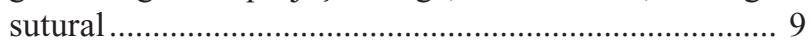

8'. Ápices elitrais com outro padrão .............................. 10 
9(7). Pronoto com alvéolos em toda superfície. (Figs. 18, 19) G. wappesi sp. nov.

9'. Pronoto com alvéolos exceto na região centro-longitudinal, ligeiramente deprimida e lisa. (Figs. 13, 15)

. G. abnormalis sp. nov.

10(8). Ápices dos élitros com projeções agudas, curtas nos ângulos sutural e marginal.

10'. Ápices elitrais com espinho no ângulo marginal e ângulo sutural agudo

11(10). Pronoto densamente alveolado e microesculturado no interior do alvéolo; base do pronoto com pequena área centro-longitudinal, lisa

G. quadrispinosa Galileo \& Martins, 2008

11'. Pronoto com alvéolos indistintos, fina e densamente áspero; base do pronoto com sulco centro-longitudinal, curto e liso. (Figs. 16, 17)

G. florida sp. nov.

12(10). Prosterno com depressão transversal na frente de cada procoxa ................................... G. invicta Martins, 1976

12'. Prosterno sem depressão transversal .....

13(12). Protórax mais longo do que largo, com lados subparalelos até a constrição basal (Figs. 5, 6) ...

G. longithorax sp. nov.

13'. Protórax, aproximadamente, tão longo quanto largo, com lados arredondados

14(13). Pronoto sem alvéolos (tegumento microesculturado e com grânulos). (Fig. 1, 2) G. tuberosa sp. nov.

14'. Pronoto com alvéolos 15

15(14). Protórax arredondado nos lados com constrição basal curta; pronoto com alvéolos pequenos, densos; depressão basal do pronoto em forma de meia lua à frente do escutelo. (Figs. 11, 12) G. alveolata sp. nov.

15'. Protórax arredondado logo abaixo do meio com constrição basal longa, bem demarcada; pronoto com alvéolos grandes e com sulco liso, centro-basal, que não alcança o meio. (Figs. 9, 10) G. guenda sp. nov.

\section{Gorybia tuberosa sp. nov.}

(Figs. 1, 2)

Tegumento castanho-claro; protórax mais avermelhado. Fronte com alvéolos microesculturados. Vértice microesculturado com grânulos esparsos (40 x). Lobos oculares superiores com quatro fileiras de omatídios. Escapo com superfície irregular, microesculturada e com grânulos $(40$ x). Antenômero III nodoso, não projetado no ápice para o lado externo. Protórax com a constrição basal mais pronunciada que a apical. Pronoto (Fig. 1) sem alvéolos com tegumento microesculturado e com grânulos (40 x). Lados do protórax com grânulos abundantes. Prosterno sem depressão transversal. Cavidades coxais anteriores abertas atrás. Élitros (Fig. 2) uniformemente castanhoclaros sem áreas mais escuras; extremidades emarginadas com espinho externo, curto no ângulo marginal e ângulo sutural agudo. Metatíbias não projetadas no ápice externo.
Dimensões em mm macho/fêmea. Comprimento total, 7,2-9,4/6,4-8,0. Protórax: comprimento, 1,6-2,0/1,4-1,7; maior largura 1,6-2,0/1,3-1,7. Élitro: comprimento, 5,1-6,8/ 4,6-5,9; largura umeral, 1,8-2,3/1,5-1,9.

Material-tipo. Holótipo macho, BOLÍVIA, Santa Cruz: Buena Vista (Hotel Fauna \& Flora, 3,7 km SSE, 430 m), 5-15.XI.2001, M. C. Thomas \& B. K. Dozier col., "black light trap, tropical transition forest" (MNKM).

Parátipos: mesmos dados da localidade do holótipo, fêmea, 1522.XI.2001, M. C. Thomas \& B. K. Dozier col., "black light trap, tropical transition forest" (ACMS); mesmo dados de localidade (4-6 km SSE), macho, 22-31.X.2002, Wappes \& Morris (MZSP); Ichilo Prov., Buena Vista (Hotel Fauna \& Flora, 4-6 km SSE, 17²9.95'S, 6333.15'W, 400-500 m), fêmea, 3-14.XI.2003, S. W. Lingafelter col., "black light" (USNM); Prov. Andrés Inbañes, Potrerillos de Guenda ( $\left.17^{\circ} 48^{\prime} \mathrm{S}, 63^{\circ} 27^{\prime} \mathrm{W}, 370 \mathrm{~m}\right)$, fêmea, 23-27.X.2007, S. W. Lingafelter col., "mv/uv lights” (ACMS).

Discussão. Gorybia tuberosa sp. nov. assemelha-se a $G$. invicta Martins, 1967 pelo pronoto finamente granulado e sem alvéolos. Difere de $G$. invicta pelas cavidades procoxais abertas atrás; pelo pronoto dos machos sem depressões e pelo prosterno sem fóvea na frente de cada procoxa. Em G. invicta, as cavidades procoxais são fechadas atrás; o pronoto dos machos tem depressões oblíquas e longitudinais e o prosterno tem duas depressões distintas na frente das procoxas.

\section{Gorybia asyka sp. nov.}

(Figs. 3, 4)

Tegumento vermelho-acastanhado; região sutural dos élitros mais avermelhada (Fig. 4). Fronte e vértice com alvéolos microesculturados internamente. Lobos oculares superiores com três fileiras de omatídios. Escapo sem grânulos, com alvéolos grandes e microesculturados. Antenômero III sem projeção no ápice externo. Protórax apenas mais largo do que longo, levemente arredondado nos lados; constrição basal bem definida e constrição anterior discreta. Pronoto (Fig. 3) com alvéolos microesculturados internamente; com sulco centro-longitudinal desde a constrição basal até quase tocar a margem anterior; esse sulco é gradualmente mais estreito para frente. Prosterno com alvéolos rasos e microesculturados internamente. Cavidades coxais anteriores fechadas atrás. Mesosterno microesculturado. Ápices dos élitros levemente oblíquos, subtruncados, ângulo marginal com espículo e ângulo sutural sub-reto. Fêmures castanho-escuros com clavas castanho-avermelhadas. Metatíbias sem projeção no ápice externo.

Dimensões em mm, macho/fêmea. Comprimento total, 8,2/7,4. Protórax: comprimento, 1,8/1,6; maior largura, 1,9/ 1,5; Élitros: comprimento, 5,9/5,2; largura umeral, 2,0/1,8.

Material-tipo. Holótipo macho, BOLÍVIA, Santa Cruz: Buena Vista (Hotel Flora \& Fauna, 4-6 km SSE), 15-20.XI.2003, R. Clarke col. (MNKM). Parátipo fêmea, mesmos dados de localidade do holótipo, 214.XI.2003, R. Clarke col. (ACMS).

Discussão. Pela presença de sulco centro-longitudinal no pronoto, Gorybia asyka sp. nov. assemelha-se a G. sulcata Martins \& Galileo, 2010. A nova espécie distingue-se pelo 

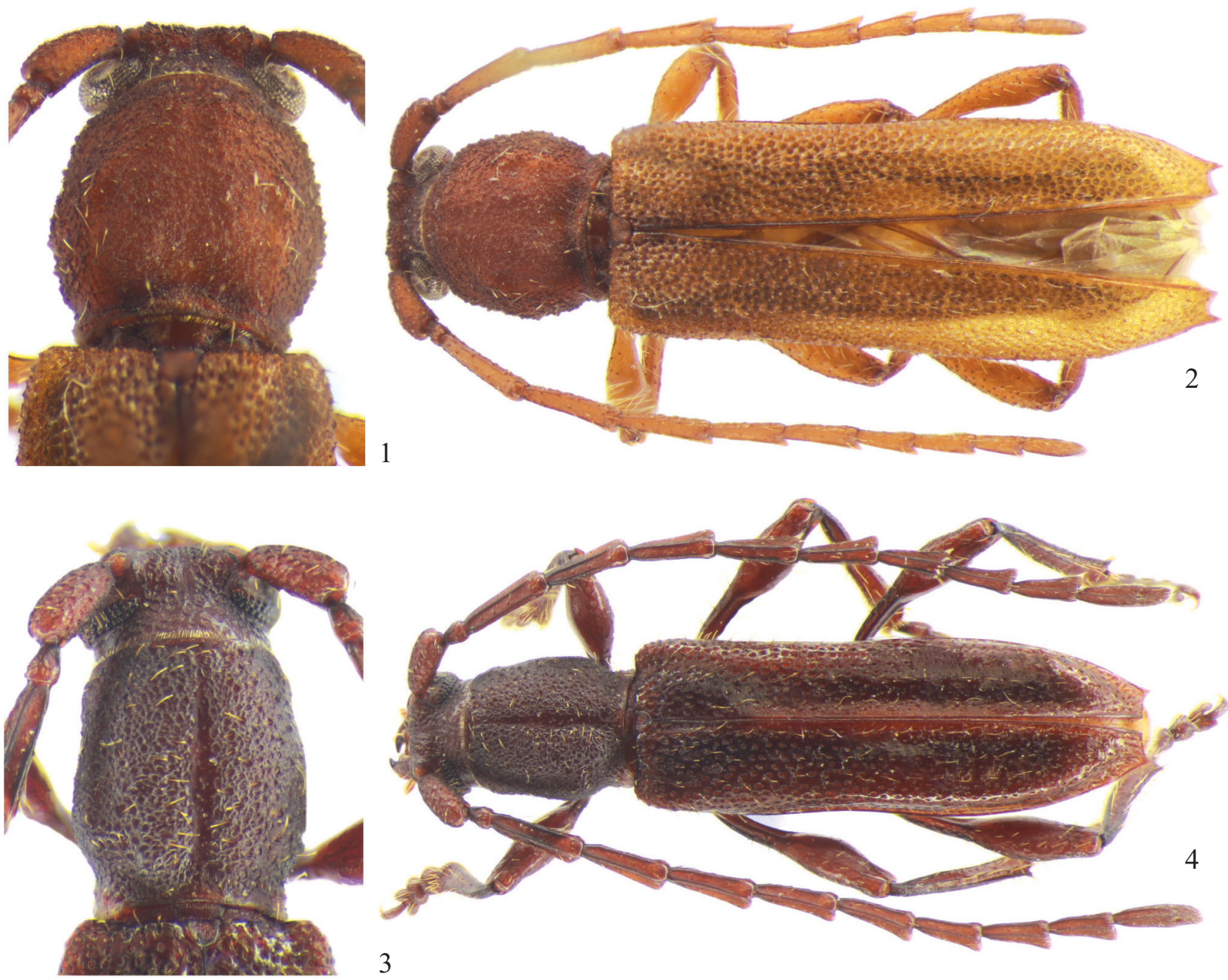

3
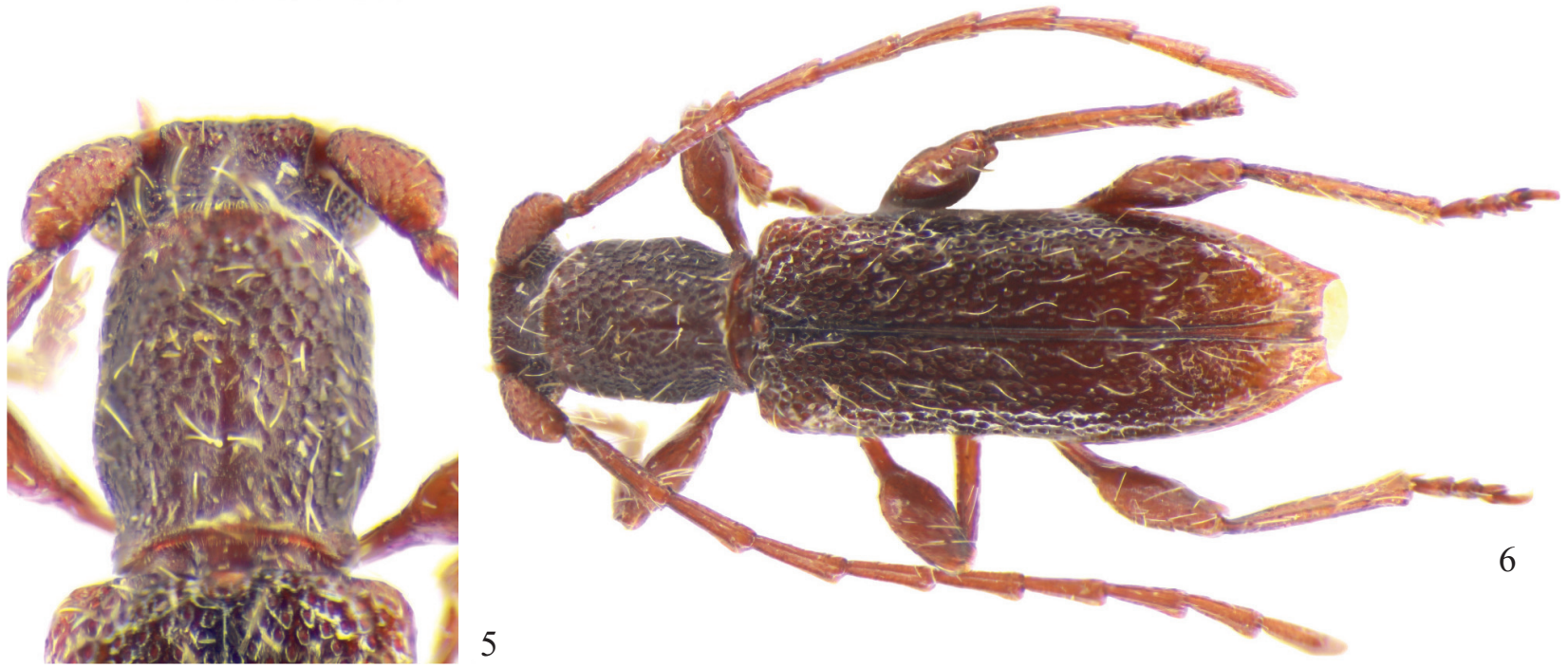

Figuras 1-6. 1-2, Gorybia tuberosa sp. nov., holótipo macho, comprimento 8,5 mm: 1, pronoto, 2, vista dorsal. 3-4, Gorybia asyka sp. nov., holótipo macho, comprimento 8,2 mm: 3, pronoto 4, vista dorsal. 5-6, Gorybia longithorax sp. nov., holótipo macho, comprimento 5,4 mm: 5, pronoto, 6, vista dorsal.

pronoto densamente alveolado, com sulco e pelos ápices dos élitros levemente oblíquos, subtruncados, com espículo no ângulo marginal e sub-reto no ângulo sutural. Em G. sulcata, os alvéolos são esparsos, o sulco do pronoto é estreito e os ápices dos élitros são emarginados com espinho longo no ângulo marginal e projeção aguda no ângulo sutural. 
Gorybia longithorax sp. nov.

(Figs. 5, 6)

Tegumento vermelho-acastanhado; antenas mais avermelhadas. Fronte e vértice alveolados e microesculturados no interior dos alvéolos. Lobos oculares superiores com três fileiras de omatídios. Antenas atingem os ápices dos élitros. Antenômero III projetado no lado externo do ápice. Protórax mais logo do que largo com longos pelos esbranquiçados; constrição anterior discreta e posterior pronunciada. Pronoto (Fig. 5) com alvéolos grandes, microesculturados internamente e uma pequena área centro-basal, lisa. Cavidades coxais anteriores fechadas atrás. Élitros (Fig. 6) com pelos aproximadamente tão longos quanto o antenômero IV; ápices elitrais emarginados, ângulo marginal com espinho curto, ângulo sutural agudo. Metatíbias projetadas no lado externo da extremidade.

Dimensões em mm, macho. Comprimento total, 5,4. Protórax: comprimento, 1,4; maior largura, 1,1. Élitros: comprimento, 3,5; largura umeral, 1,4.

Material-tipo. Holótipo macho, BOLÍVIA, Santa Cruz: Província Ichilo (Buena Vista, Hotel Flora \& Fauna, 17²9,95'S, 6333,15’W, 400-500 m), 3-14.XI.2003, S. W. Lingafelter col., black light (MNKM).

Discussão. Gorybia longithorax sp. nov. caracteriza-se pelo protórax alongado e pelos élitros com pelos longos.

\section{Gorybia inarmata sp. nov.}

(Figs. 7, 8)

Tegumento vermelho-acastanhado; flagelômeros apicais ligeiramente mais claros. Fronte e vértice alveolados; alvéolos microesculturados internamente. Lobos oculares superiores com três fileiras de omatídios. Escapo com superfície irregular, com alvéolos grandes e próximos. Antenômero III não projetado na extremidade. Protórax apenas mais largo do que longo com a constrição posterior mais acentuada que a anterior. Pronoto (Fig. 7) com alvéolos rasos, microesculturados internamente. Cavidades coxais anteriores fechadas atrás. Élitros (Fig.8) com pelos curtos, organizados em quatro fileiras irregulares. Extremidades elitrais obliquamente truncadas e desarmadas. Metatíbias sem projeção apical externa.

Dimensões em mm, fêmea. Comprimento total, 8,5. Protórax: comprimento, 1,7; maior largura, 1,8. Élitros: comprimento, 6,2; largura umeral, 2,0.

Material-tipo. Holótipo fêmea, BOLÍVIA, Santa Cruz: El Refúgio, Los Volcanes (3363 “feet”), 1-10.X.2008, Morris \& Wappes col. (MNKM).

Discussão. Ápices dos élitros obliquamente truncados e desarmados não ocorrem nas espécies bolivianas de Gorybia. Pelo aspecto do protórax Gorybia inarmata sp. nov. lembra G. thoracica Martins, 1976. A nova espécie difere de $G$. thoracica pelo pronoto sem gibosidades. Em G. thoracica, o pronoto tem duas gibosidades arredondadas.

\section{Gorybia guenda sp. nov.}

(Figs. 9, 10)

Tegumento vermelho-acastanhado; antenas, fêmures e élitros mais avermelhados. Fronte e vértice alveolados, microesculturados no interior dos alvéolos. Lobos oculares superiores com três fileiras de omatídios. Escapo alveolado, sem grânulos. Antenômero III não projetado no ângulo externo. Protórax tão largo quanto longo; constrição anterior discreta e constrição posterior longa, bem demarcada. Pronoto (Fig. 9) alveolado; com sulco liso que vai do terço basal até pouco acima do meio (menos evidente nas fêmeas). Cavidades procoxais abertas atrás. Élitros (Fig. 10) com pelos curtos organizados em cinco fileiras irregulares. Ápices elitrais emarginados com espinho curto no ângulo marginal e ângulo sutural agudo, levemente projetado. Esta projeção tão longa quanto metade (macho) ou um terço (fêmea) do espinho sutural. Metatíbias sem projeção do ápice externo.

Dimensões em mm, macho/fêmea. Comprimento total, 7,0/6,6. Protórax: comprimento, 1,5/1,6; maior largura, 1,5/ 1,5. Élitros: comprimento, 5,1/5,3; largura umeral, 1,8/1,7.

Material-tipo. Holótipo macho, BOLÍVIA, Santa Cruz: Potrerillos del Guenda (40 km NW de Santa Cruz). 1-10.X.2008, Wappes \& Morris col. (MNKM). Parátipo fêmea, com os mesmos dados do holótipo (ACMS).

Discussão. Gorybia guenda sp. nov. assemelha-se a $G$. hirsutella Martins, 1976, ambas têm sulco liso na metade posterior do pronoto. G. guenda difere pelo espinho marginal do ápice dos élitros mais curto e pelo antenômero III não projetado no ápice externo. Em G. hirsutella, o espinho marginal do ápice dos élitros é longo e largo na base e o antenômero III é projetado em dente no ápice externo.

Gorybia guenda sp. nov. também pode ser comparada com G. bispinosa Martins et al., 2009, pelos ápices dos élitros com projeção curta nos dois ângulos; difere: pelas dimensões menores; pela presença de sulco liso na base do pronoto e pelos élitros com pelos mais curtos. Em G. bispinosa, figurada por Martins et al. 2009: 519, fig. 8), as dimensões são maiores (comprimento, 9,8 $\mathrm{mm}$, largura umeral, 2,4 $\mathrm{mm}$ ); o pronoto não tem sulco basal e os élitros têm pelos mais longos.

\section{Gorybia alveolata sp. nov.}

(Figs. 11, 12)

Tegumento avermelhado. Fronte e vértice microesculturados, com alvéolos indistintos e grânulos pequenos $(40 \mathrm{x})$. Lobos oculares superiores com quatro fileiras de omatídios. Antenas (macho) atingem os ápices dos élitros. Escapo com superfície irregular e grânulos. Antenômero III não projetado na extremidade externa. Protórax bem arredondado nos lados; constrição posterior mais pronunciada que a anterior e em pequena extensão. Pronoto (Fig. 11) com alvéolos pequenos, densos e microesculturados em toda superfície; depressão à frente do escutelo em forma de meia lua. Lados do protórax e prosterno com alvéolos e grânulos como no 

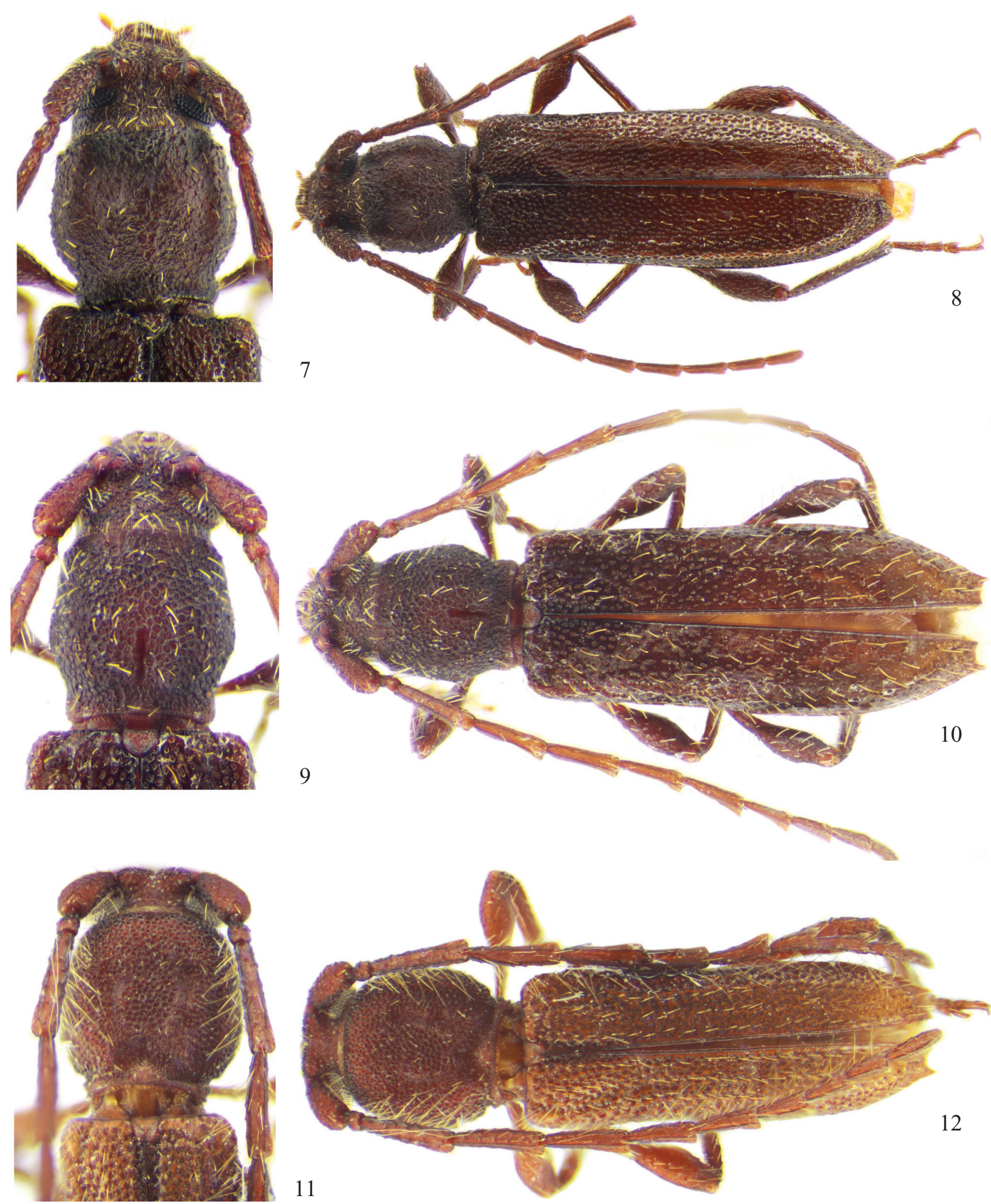

Figuras 7-12. 7-8, Gorybia inarmata sp. nov., holótipo fêmea, comprimento 8,5 mm: 7, pronoto, 8, vista dorsal. 9-10, Gorybia guenda sp. nov., holótipo macho, comprimento 7,0 mm: 9, pronoto, 10, vista dorsal. 11-12, Gorybia alveolata sp. nov., holótipo macho, comprimento 5,7 mm: 11, pronoto, 12, vista dorsal.

pronoto. Metasterno liso. Cavidades coxais anteriores abertas atrás. Élitros (Fig. 12) com pelos elitrais organizados em cinco fileiras irregulares; ápices emarginados com espinho marginal curto e ângulo sutural agudo, levemente projetado.
Metatíbias não projetadas no ápice externo.

Dimensões em mm, macho. Comprimento total, 5,7-5,8. Protórax: comprimento, 1,4-1,5; maior largura, 1,4-1,5. Élitros: comprimento, 3,9-4,1; largura umeral, 1,4-1,5. 
Material-tipo. Holótipo macho, BOLÍVIA, Santa Cruz: Buena Vista (Hotel Flora \& Fauna, 3.7 km SSE, 430 m), 15-22.XI.2001, B. K. Dozier col. "blacklight trap, transition forest" (MNKM). Parátipos - mesma localidade do holótipo, (4-6 km SSE), macho, 21-24.XI.2003, Wappes, Morris \& Nearns col. (MZSP); macho, 3-8.X.2004, Wappes \& Morris col. (ACMS); Santa Cruz: Provincia Ichilo, Buena Vista (Hotel Flora \& Fauna, 4-6 km SSE, $17^{\circ} 29,95^{\prime} \mathrm{S}, 63^{\circ} 33,15^{\prime} \mathrm{W}, 400-500 \mathrm{~m}$ ), macho, 3-14.XI.2003, S. W. Lingafelter col., "beating" (ACMS). Santa Cruz: Potrerillos del Guenda $\left(17^{\circ} 40,26 \mathrm{~S} 63^{\circ} 27,43 \mathrm{~W}, 400 \mathrm{~m}\right)$, macho. 16-21.X.2006, Nearns, Wappes \& Eya col, "ultraviolet light" (ACMS).

Discussão. Caracteres que distinguem $G$. alveolata sp. nov.: protórax com lados arredondados; pronoto com alvéolos finos e densos e com marcada depressão em meia lua adiante do escutelo.

\section{Gorybia abnormalis sp. nov.}

(Figs. 13-15)

Tegumento vermelho-acastanhado. Fronte e vértice distintamente alveolados. Lobos oculares superiores com três fileiras de omatídios. Antenas atingem o quarto apical dos élitros. Escapo alveolado, sem grânulos e microesculturado. Antenômero III com projeção curta no lado interno do ápice. Protórax levemente abaulado nos lados e fortemente constrito na base. Pronoto (Figs. 13, 15) com alvéolos exceto na região centro-longitudinal, sem alvéolos e ligeiramente deprimida; essa depressão vai do adelgaçamento basal até quase o terço basal. Lados do protórax com alvéolos. Prosterno com superfície irregular, com alvéolos mais densos lateralmente. Metasterno brilhante. Cavidades coxais anteriores abertas atrás. Superfície elitral brilhante. Extremidades dos élitros (Fig. 14) com espinho curto externo e projeção larga, arredondada, no lado interno. Metatíbias projetadas no lado externo da extremidade.

Dimensões em mm, macho/fêmea Comprimento total, 4,7-5,0/3,1-5,3. Protórax: comprimento, 1,1-1,2/0,9-1,2; maior largura, 1,0-1,1/0,8-1,1. Élitros: comprimento, 3,3-3,4/ 2,5-3,6; largura umeral, 1,1-1,2/0,9-1,4

Material-tipo. Holótipo fêmea, BOLÍVIA, Santa Cruz: Buena Vista (Hotel Flora \& Fauna, 4-6 km SSE), 23-28.X.2000, Wappes \& Morris col. (MNKM). Parátipos - mesma localidade do holótipo, macho, 22-31.X.2002, Wappes \& Morris col. (ACMS); macho, 14-19.X.2003, R. Clarke col. (MZSP); macho, 15-20.X.2003, R. Clarke col. (ACMS); 2 machos, 38.X.2004, Wappes \& Morris col. (ACMS); macho, 19-22.X.2004, Wappes \& Morris col. (MZSP); fêmea?, 11-12.III.2011, J. Wappes \& D. Thomas col. (ACMS). Santa Cruz: Prov. Andres Ibañez: Potrerillos del Guenda (1740’S, $63^{\circ} 27^{\prime} \mathrm{W}, 370 \mathrm{~m}$ ), macho, 23-27.X.2007, S. W. Lingafelter col. (ACMS).

Discussão. Gorybia abnormalis sp. nov. caracteriza-se pelo ápice dos élitros com modificação do espinho sutural em uma projeção sensivelmente mais larga que nas demais espécies do gênero (exceto $G$. wappesi descrita abaixo e comparada).

\section{Gorybia florida sp. nov.}

(Figs. 16, 17)

Tegumento vermelho-acastanhado; cabeça e protórax castanho-escuros. Fronte e vértice com alvéolos rasos e microesculturados. Lobos oculares superiores com três fileiras de omatídios. Antenas atingem as extremidades dos élitros aproximadamente no ápice do antenômero X. Escapo sem grânulos, com alvéolos grandes. Antenômero III sem projeção no ápice externo. Protórax com constrição anterior muito discreta e a posterior bem acentuada. Pronoto (Figs. $16,17)$ com alvéolos indistintos, fina e densamente áspero, com sulco longitudinal, centro-basal, curto e liso. Prosterno liso e quase sem pontos. Cavidades procoxais fechadas atrás. Metasterno liso, brilhante com microescultura na base e estreitamente nos lados. Ápices elitrais emarginados com projeções agudas muito curtas nos dois ângulos. Metatíbias sem projeção apical externa.

Dimensões em mm, macho. Comprimento total, 6,7. Protórax: comprimento,1,4; largura da constrição anterior, 1,2; largura da constrição posterior, 1,0. Élitro: comprimento, 4,7; largura umeral, 1,6.

Material-tipo. Holótipo macho, BOLÍVIA, Santa Cruz: Prov. Florida (Refugio Los Volcanes, 4 km N Bermejo, 1806'S, 6336' W, 1045-1200 m), 28.X-5.XI.2007, S. W. Lingafelter col., “day coll.” (MNKM).

Discussão. Gorybia florida sp. nov. pode ser comparada com $G$. inarmata sp. nov. por terem protórax com formato semelhante. Distingue-se: pelo pronoto com alvéolos indistintos, fina e densamente áspero; pelos élitros com pelos mais longos e pelos ápices dos élitros emarginados, com projeções agudas, subiguais, nos ângulos marginal e sutural. Em $G$. inarmata, o pronoto tem alvéolos mais distintos e microesculturados internamente; os pelos dos élitros são mais curtos e os ápices dos élitros são obliquamente truncados e desarmados.

\section{Gorybia wappesi sp. nov.}

(Figs. 18, 19)

Etimologia. O epíteto é uma homenagem a J. E. Wappes pesquisador entusiasmado da fauna cerambicidológica da Bolívia.

Tegumento vermelho-acastanhado. Fronte e vértice com alvéolos grandes internamente microesculturados. Tubérculos anteníferos algo projetados. Lobos oculares superiores com três fileiras de omatídios. Antenas atingem o sexto apical dos élitros. Escapo alveolado, microesculturado e sem grânulos. Antenômero III com projeção curta no lado interno do ápice. Protórax levemente abaulado nos lados, fortemente constrito na base; alveolado nos lados. Lados do protórax e pronoto (Fig. 18) com alvéolos em toda superfície. Prosterno liso. Metasterno com microescultura nos lados. Cavidades coxais anteriores abertas atrás. Élitros (Fig. 19) com superfície brilhante; pelos de comprimento médio; ápices emarginados com espinho curto no ângulo marginal e projeção aguda no ângulo sutural. Metatíbias projetadas no lado externo da extremidade.

Dimensões em mm, macho/fêmea. Comprimento total, 5,0-6,3/4,6-7,1. Protórax: comprimento, 1,1-1,4/1,0-1,5; maior largura do protórax, 0,95-1,2/0,9-1,4. Élitro: comprimento 3,5-4,5/3,3-5,1; largura umeral, 1,1-1,5/1,1-1,8. 

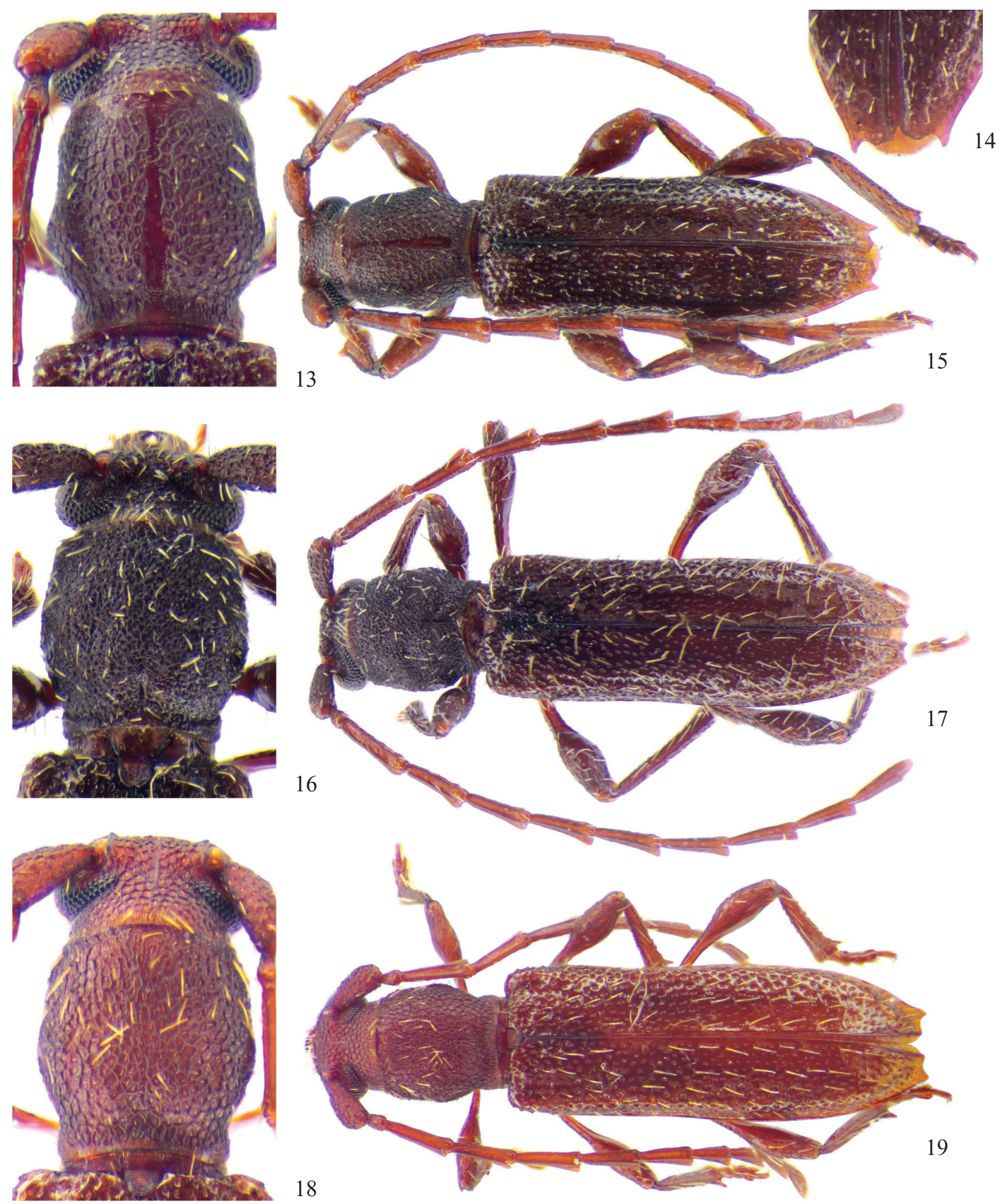

Figuras 13-19. 13-15, Gorybia abnormalis sp. nov., parátipo macho, comprimento 4,5 mm: 13, pronoto, 14, ápice dos élitros, 15, vista dorsal. 16-17, Gorybia florida sp. nov., holótipo macho, comprimento $6,7 \mathrm{~mm}$ : 16, pronoto, 17, vista dorsal. 18-19, Gorybia wappesi sp. nov., parátipo macho, comprimento $6,0 \mathrm{~mm}: 18$, pronoto, 19 , vista dorsal.

Material-tipo. Holótipo macho, BOLÍVIA, Santa Cruz, Buena Vista (Hotel Flora \&Fauna. 4-6 km SSE), 1-14.X.2003, R. Clake col. (MNKM).

Parátipos - "Ost Bolivia" fêmea, 8.XII.1906 Steinbach col. Beni: Río Itenez at mouth of Río Baures, fêmea, XI-X.1964, J. K. Bouseman \& J. Lussenhop col. (AMNH); Río Yacuma, Espirtu (250 m), fêmea, 25.IV.1954,
W. Foster col. (USNM); Santa Cruz: Buena Vista, macho, 18-25.X.1992, E. Giesbert col.; (Hotel Flora \& Fauna, 4-6 km SSE), fêmea, 23-26.X.2000, Wappes \& Morris col.; 2 machos, 2 fêmeas, 1-16.IV.2003, R. Clarke col. (macho, ACMS; macho, fêmea, MZSP; fêmea MCNZ); fêmea, 2-14.X.2003, R, Clarke col.; 2 fêmeas, 17-30.IV.2003, R. Clarke col. (ACMS); fêmea, 
20-30.X.2003, R. Clarke col. (ACMS). Santa Cruz: Potrerillos del Guenda (370 m), fêmea, 10-15.X.2007, J. Wappes \& A. Cline col. (MZSP); fêmea, 16-21.X.2007, F. \& J. Romero col. (MZSP).

Discussão. Gorybia wappesi sp. nov. é semelhante a $G$. abnormalis pelo ângulo sutural dos élitros com projeção arredondada. Difere pelo pronoto inteiramente alveolado, sem sulco centro-longitudinal. Em G. abnormalis o pronoto é alveolado exceto na região centro-longitudinal, ligeiramente deprimida e lisa. Assemelha-se também a G. stomias Martins, 1976 pelas pequenas dimensões, mas difere pelo antenômero III projetado na extremidade e pelo ápice dos élitros com espinho externo menos desenvolvido.

\section{AGRADECIMENTOS}

A James E. Wappes (ACMS) e outros membros do "Bolivia Cerambycidae Project” (Dozier, Lingafelter, Morris e Thomas) pelo empréstimo de material; a Eugenio H. Nearns (Museum of Southwestern Biology, University of New México) e Antonio Santos Silva (MZSP) pela leitura e correções no manuscrito; a Eleandro Moysés (Bolsista PIBIC/CNPq/FZB/RS) pela execução das fotografias e tratamento das imagens.

\section{REFERÊNCIAS}

Bates, H.W. 1870. Contributions to an insect fauna of the Amazon Valley.

Transactions of the Entomological Society of London 1870: 243-
$335 ; 391-444$

Galileo, M.H.M. \& Martins, U.R. 2008. Novos Cerambycinae (Cerambycidae) da Região Neotropical. Papéis Avulsos de Zoologia 48: 49-54.

Galileo, M.H.M. \& Martins, U.R. 2010. New species of Cerambycinae (Coleoptera, Cerambycidae) from South America. Insecta Mundi 0115: $1-9$.

Gounelle, E. 1909. Liste des cérambycides de la région de Jatahy, Etat de Goyaz, Brésil. Annales de la Societé Entomologique de France 77: $587-688$.

Martins, U.R. 1976. Sistemática e evolução da tribo Piezocerini. Arquivos de Zoologia 27: 165-370.

Martins, U.R. 2003. Tribo Piezocerini, p. 65-201. In: Cerambycidae sulamericanos (Coleoptera). vol. 6. São Paulo, Sociedade Brasileira de Entomologia, vii $+232 \mathrm{p}$.

Martins, U.R. \& Galileo, M.H.M. 2007. Novos Cerambycidae (Coleoptera) da Coleção Odette Morvan, Kaw, Guiana Francesa. Papéis Avulsos de Zoologia 47: 175-179.

Martins, U.R., Galileo, M.H.M. \& Limeira-de-Oliveira, F. 2009. Cerambycidae (Coleoptera) do estado do Maranhão, Brasil II. Papéis Avulsos de Zoologia 49: 503-527.

Martins, U.R. \& Galileo, M.H.M. 2010. Notas e descrições em Hesperophanini, Eburiini, Piezocerini e Trachyderini (Coleoptera, Cerambycidae, Cerambycinae) do Brasil e da Bolívia. Papéis Avulsos de Zoologia 50: 587-593.

Pascoe, F.P. 1866. Notes on Sphaerion and Mallocera. Annals and Magazine of Natural History 18: 477-484.

Wappes, J.E., Morris II, R.F., Nearns, E.H. \& Thomas, M.C. 2006. Preliminary checklist of Bolivian Cerambycidae (Coleoptera). Insecta Mundi 20: 1-45.

Wappes, J.E., Lingafelter, S.W. \& Perger, R. 2011. Additions and deletions to the known Cerambycidae (Coleoptera) of Bolivia. Insecta Mundi 0150: $1-8$. 